\title{
The development of a dental trauma application in Portuguese Language
}

\author{
Beatriz Silva de Souza, ${ }^{1}$ Aryane Mayara Ferreira Ribeiro, ${ }^{1}$ Carolina Oliveira de Lima, ${ }^{2}$ Emmanuel João Nogueira Leal da Silva ${ }^{1,2}$ \\ ${ }^{1}$ Department of Endodontics, School of Dentistry, Grande Rio University (UNIGRANRIO), Rio de Janeiro, RJ, Brazil \\ ${ }^{2}$ Department of Endodontics, School of Dentistry, State University of Rio de Janeiro (UERJ), Rio de Janeiro, RJ, Brazil \\ - Conflicts of interest: none declared.
}

\section{Dear editor,}

$\mathrm{T}$ Traumatic dental injuries (TDIs) occur frequently in children of pre-school, school age and young adults and account for $5 \%$ of all injuries leading to inpatient or outpatient treatment and that the oral region is the sixth most frequently injured part of the body. ${ }^{1,2} \mathrm{~A}$ literature review reports that $25 \%$ of all school-age children suffered some kind of dental traum and that $33 \%$ of adults suffered permanent dentition trauma, with most of these injuries occurring before 19 years old. ${ }^{3}$ Dislocations are the most common TDIs in the deciduous dentition, while coronary fractures are most commonly reported in the permanent dentition. ${ }^{1,4,5}$ TDIs represent a challenge for clinicians worldwide. Consequently, adequate diagnosis, treatment plan and follow-up are essential to ensure a favorable prognosis.

The present guidelines of the International Association of Dental Traumatology (IADT) represent an updated set of guidelines, based on the original guidelines published in $2007 .^{6-8}$ The update was performed based on a literature review using the EMBASE, MEDLINE and PUBMED databases with searches between the 1996-2011 periods, as well as a survey of the contents of the Dental Traumatology journal of the 2000-2011 periods. These guidelines should assist dentists, other health care professionals, and patients in the decision-making process. Also, they are credible, practical and easy to understand, in order to provide the most efficient and effective service possible.

The main objective of these guidelines is to outline an approach for the immediate or urgent care of TDIs. It is understood that subsequent treatment of TDIs may require secondary and tertiary interventions involving specialized consultations, services, and/or materials/methods not always available during primary care. However, these guidelines is often difficult to access and understand, even for dentists and other health professionals. Historically, audiovisual methods such as educational posters have been suggested as a clear, accessible and low-cost method to improve the knowledge of dental trauma. ${ }^{9}$ However, access to information is now reaching new heights and the use of software applications (apps) in smartphones has been indicated as an useful tool to increase dental trauma knowledge and management..$^{10,11}$ Nonetheless, most of these dental trauma apps are available only in English language which makes it unfeasible for users not familiar with the language.

The aim of the present study was to develop a software application using an open source platform with data related to dental trauma and its treatment for dentists, health professionals and general public in Portuguese language.

\section{The Dental Trauma app}

The Trauma Dental app was developed natively for both iOS and Android operating systems by a multidisciplinary team. To create the app, a didactic plan related to bibliographic data search, mainly using the Dental Trauma Guidelines, ${ }^{12-14}$ was determined. Software development was performed using the open source platform "Fábrica de Aplicativos" (https://fabricadeaplicativos.com.br/) (Figure 1). The app functions as a self-contained tool to provide dental trauma and emergency conduct to both dentists and patients (Figure 2) and may be used by either novice or experienced users. The app has icons with all possible trauma categories under primary and permanent dentition (Figure 3). Additionally, the app contains information regarding how to prevent dental trauma. Also, the app include an email for feedback and support where users are permitted to provide suggestions for app improvements, report bugs, and request technical assistance.

\section{Discussion}

Management of traumatic dental injuries it is complex due many variables involved as combination injuries and interval between dental trauma and the onset of endodontic intervention. ${ }^{7}$ Correct diagnosis and appropriate initial treatment is a critical factor in predicting the long-term prognosis. ${ }^{12}$ So, dentists should know about the type of trauma and appropriate treatment. ${ }^{9}$

Applications have become an important element of smartphones and tablets since their emergence in $2008^{15}$ and it has been used by dentists and other healthcare workers as part 
of their professional practice like a diagnostic tool. ${ }^{16}$ These applications can improve the quality of care, specifically in remote areas without access to providers and create opportunities to integrate technology into daily clinical practice. ${ }^{17}$
The use of software applications like "Trauma Dental" facilitates in differential diagnosis and initial treatment of dental trauma ${ }^{10}$ and has portability, cost effective, and it is easily available, because dentists can download it at smart-

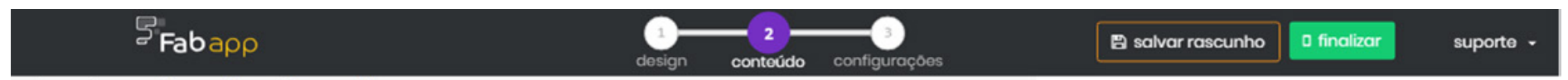

Arraste e solte a aba até o celular para adicionar o conteúdo

$\begin{gathered}\text { album do } \\ \text { fotos }\end{gathered}$
$\begin{gathered}\text { álbum pro } \\ \text { listado } \\ \text { toxtos }\end{gathered}$
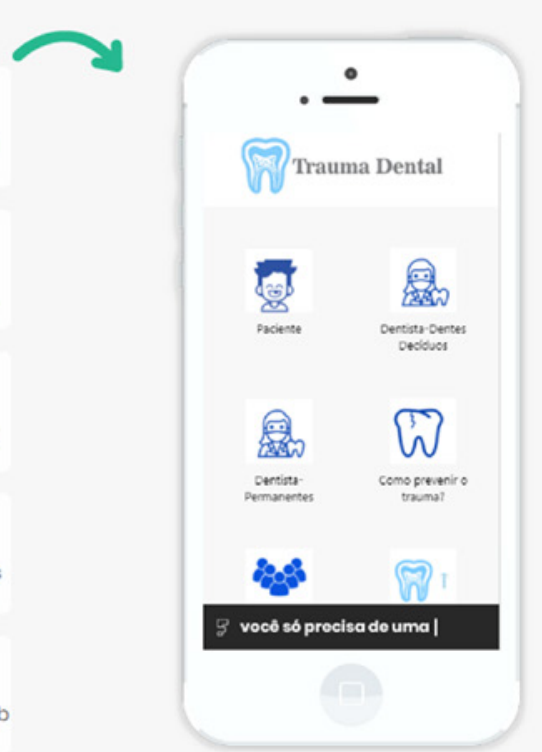

arraste uma aba para que seja a principal no
seupp

Figure 1. Interface of open source platform "Fábrica de Aplicativos"

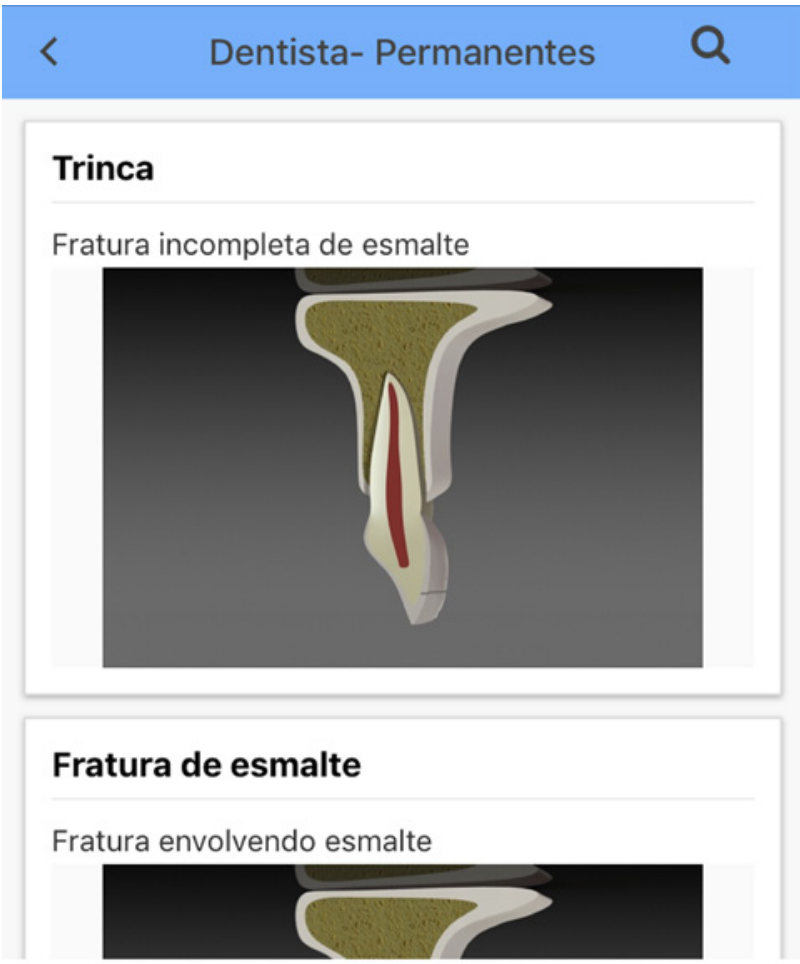

www.fabricadeaplicativos.com.br

\section{www.fabricadeaplicativos.com.br}

Figure 2. Interface of application "Trauma Dental" and the functions available to the patient and dentists in primary and permanent dentition trauma

\section{Trauma Dental}


phones. ${ }^{18}$ Some studies evaluated the effectiveness of different apps in correct diagnosis of dental trauma and verified that apps are effective in assisting the diagnosis of dental trauma. . $^{10,11,18,19}$

There are many applications in English language available for both patients and dentists in the emergency management of traumatic dental injuries - like Trauma First Aid, Dental Crown Repair i.e., ${ }^{18}$ however applications following the Dental Trauma Guidelines, ${ }^{12-14}$ in Portuguese language are limited.

The Portuguese language is spoken by 263 million people, which represents $3.7 \%$ of the world population and it is considered the 4 th most spoken language in the world. ${ }^{20}$ In addition, the prevalence rate of dental trauma in Brazilian population varied from $7.2 \%$ to $58.6 \% .{ }^{21-23}$ Due to the high prevalence of trauma in the Brazilian population and the large number of Portuguese speakers, the development of "Trauma Dental" application, in Portuguese language, it will facilitates access to information on diagnosis and treatment of dental trauma for the general public, dentists and people from different countries who speak the Portuguese language.

\section{Acknowledgements}

The authors deny any conflicts of interest related to this study.

\section{References}

1. Andreasen JO, Andreasen FM, Andersson LA. Textbook and color atlas of traumatic injuries to the teeth. 4th ed: Oxford, UK; 2007.

2. Petersson EE, Andersson L, Sörensen S. Traumatic oral vs non-oral injuries. Swed Dent J. 1997;21(1-2):55-68.

3. Glendor U. Epidemiology of traumatic dental injuries--a 12 year review of the literature. Dent Traumatol. 2008;24(6):603-11.

4. Flores MT. Traumatic injuries in the primary dentition. Dent Traumatol. 2002;18(6):287-98.

5. Kramer PF, Zembruski C, Ferreira SH, Feldens CA. Traumatic dental injuries in Brazilian preschool children. Dent Traumatol. 2003;19(6):299-303.

6. Flores MT, Andersson L, Andreasen JO, Bakland LK, Malmgren B, Barnett F, et al. Guidelines for the management of traumatic dental injuries. II. Avulsion of permanent teeth. Dent Traumatol. 2007;23(3):130-6.

7. Flores MT, Malmgren B, Andersson L, Andreasen JO, Bakland LK, Barnett F, et al. Guidelines for the management of traumatic dental injuries. III. Primary teeth. Dent Traumatol. 2007;23(4):196-202.

8. Flores MT, Andersson L, Andreasen JO, Bakland LK, Malmgren B, Barnett F, et al. Guidelines for the management of traumatic dental injuries. I. Fractures and luxations of permanent teeth. Dent Traumatol. 2007;23(2):66-71.

9. Soubra BN, Debs NN. Impact of audiovisual method in educating children facing dental avulsion. Dent Traumatol. 2014;30(3):216-21.

10. Mohan A, Agarwal T, Cherian TS, Muthu MS, Balasubramanian S, Subbalekshmi N, et al. Diagnostic ability of a smart phone app (injured tooth) in diagnosing traumatic injuries to the teeth - a multicentre analysis. Int J Paediatr Dent. 2018;28(6):561-9.

11. Zaror C, Espinoza-Espinoza G, Atala-Acevedo C, Muñoz-Millán P, Li Y, Clarke K, et al. Validation and usability of a mobile phone application for epidemiological surveillance of traumatic dental injuries. Dent Traumatol. 2019;35(1):33-40.

12. Andersson L, Andreasen JO, Day P, Heithersay G, Trope M, Diangelis AJ, et al. International Association of Dental Traumatology guidelines for the management of traumatic dental injuries: 2 . Avulsion of permanent teeth. Dent Trauma-

tol. 2012;28(2):88-96.

13. Diangelis AJ, Andreasen JO, Ebeleseder KA, Kenny DJ, Trope M, Sigurdsson A, et al. International Association of Dental Traumatology guidelines for the management of traumatic dental injuries: 1 . Fractures and luxations of permanent teeth. Dent Traumatol. 2012;28(1):2-12.

14. Malmgren B, Andreasen JO, Flores MT, Robertson A, DiAngelis AJ, Andersson $\mathrm{L}$, et al. International Association of Dental Traumatology guidelines for the management of traumatic dental injuries: 3 . Injuries in the primary dentition. Dent Traumatol. 2012;28(3):174-82.

15. Lupton D, Jutel A. 'It's like having a physician in your pocket!' A critical analysis of self-diagnosis smartphone apps. Soc Sci Med. 2015;133:128-35.

16. Buijink AW, Visser BJ, Marshall L. Medical apps for smartphones: lack of evidence undermines quality and safety. Evid Based Med. 2013;18(3):90-2.

17. Dhuvad JM, Dhuvad MM, Kshirsagar RA. Have Smartphones Contributed in the Clinical Progress of Oral and Maxillofacial Surgery? J Clin Diagn Res. 2015;9(9):ZC22-4.

18. Djemal S, Singh P. Smartphones and dental trauma: the current availability of apps for managing traumatic dental injuries. Dent Traumatol. 2016;32(1):52-7. 19. Machado JP, Lam XT, Chen JW. Use of a clinical decision support tool for the management of traumatic dental injuries in the primary dentition by novice and expert clinicians. Dent Traumatol. 2018;34(2):120-8.

20. Reto L, Esperança LMJP. New Atlas of the Portuguese Language. Hardcover; 2016.

21. Soriano EP, Caldas AeF, Diniz De Carvalho MV, Amorim Filho HeA. Prevalence and risk factors related to traumatic dental injuries in Brazilian schoolchildren. Dent Traumatol. 2007;23(4):232-40.

22. Marcenes W, Zabot NE, Traebert J. Socio-economic correlates of traumatic injuries to the permanent incisors in schoolchildren aged 12 years in Blumenau, Brazil. Dent Traumatol. 2001;17(5):222-6.

23. Antunes LA, Rodrigues AS, Martins AM, Cardoso ES, Homsi N, Antunes LS. Traumatic dental injury in permanent teeth: knowledge and management in a group of Brazilian school teachers. Dent Traumatol. 2016;32(4):269-73.

\section{Mini Curriculum and Author's Contribution}

1. Beatriz Silva de Souza - DDS. Contribution: development of application software. ORCID: 0000-0002-5924-5649

2. Aryane Mayara Ferreira Ribeiro - DDS. Contribution: development of application software. ORCID: 0000-0002-2300-0156

3. Carolina Oliveira de Lima - DDS; MSc. Contribution: write the manuscript. ORCID: 0000-0003-2132-4373

4. Emmanuel João Nogueira Leal da Silva - DDS; PhD. Contribution: idea, hypothesis, proofread the manuscript and final approval of the version to be published. ORCID: 0000-0002-6445-8243

Submitted: 02/19/2019 / Accepted for publication: 05/19/2019

\section{Corresponding Author}

Emmanuel João Nogueira Leal da Silva

E-mail: nogueiraemmanuel@hotmail.com 